\title{
Strategy of innovative development of animal husbandry in the Bryansk region
}

\author{
V.F. Vaskin ${ }^{1}$, O.N. Korosteleva ${ }^{1}$, A.A. Kuzmitskaya ${ }^{1 . *}$, V.I. Repnikova ${ }^{1}$, and T.M. \\ Khvostenko ${ }^{2}$ \\ ${ }^{1}$ Bryansk State Agrarian University, 241037 Bryansk, Russia \\ ${ }^{2}$ Bryansk Institute of Management and Business, 243365 Bryansk, Russia
}

\begin{abstract}
The article substantiates the strategy of innovative development of animal husbandry in the Bryansk region. The main indicators of animal husbandry development are studied. The dynamics of the population of animals, poultry, rabbits and bee colonies is analyzed. The structure and dynamics of livestock products manufacturing, including the production of cattle and poultry in carcass weight, milk, eggs and honey, are calculated. The productivity of animals is estimated, including the average daily weight gain of cattle and pigs, the average annual milk yield per cow, and the average annual egg production of laying hens. The best practices of animal husbandry effective development on an innovative basis are considered. Major investment projects implemented in the livestock industry are considered. The scenario forecast of production of the most important types of animal products (milk and meat of cattle and poultry) is presented. The directions of the strategic development of the industry are justified.
\end{abstract}

\section{Introduction}

Russia has adopted a Strategy for the development of the agro-industrial and fisheries complexes of Russia until 2030. This Strategy is aimed at stimulating positive structural changes in the industry, and includes the goals and measures of a long-term economic policy in relation to the agro-industrial complex. The implementation of the Strategy is planned in two stages: first stage - until 2024, second stage - from 2025 to 2030. The results of 2019 were selected as the basic parameters and indicators with which further progress is to be compared $[1,2]$.

In the field of agriculture, the basis of state policy is planned to be formed from eight goals:

1. Increasing the share of the total area of well-maintained residential premises in rural settlements (state program "Integrated development of rural areas").

2. Increasing the ratio of the average monthly available resources of rural and urban households.

3. Increasing the value added produced in the agro-industrial complex.

4. Increasing the physical volume of investments in the agro-industrial complex.

*Corresponding author: Anna_Kuzm79@mail.ru 
5. Increasing the volume of exports to the level of at least $\$ 45$ billion per year.

6. Ensuring food security.

7. Digital transformation of the agro-industrial complex (creation of the Digital Agriculture platform).

8. Improving the scientific and technological level of the agro-industrial complex through the development of breeding and genetics.

The strategy will be implemented in difficult macroeconomic conditions, and the performance of the indicators will be affected by serious risks. However, the implementation of the Strategy will strengthen the role of Russia as a reliable supplier of agricultural products to the domestic market, strengthen the role of Russia as a reliable exporter, and increase the corresponding volumes of agricultural exports.

Agriculture of the Bryansk region is the most important branch of the region's economy. Thanks to state support and efficient, innovation-oriented production activities of agricultural enterprises, agriculture in the region is an attractive investment sector of the economy [3-6]. Further development of the agricultural sector of the region is aimed at progressive development in accordance with the defining parameters of the Strategy for the Development of the Agro-industrial complex of Russia until 2030.

\section{Materials and methods}

The methodological basis of the study was the developments of research institutions, domestic scientists studying the problems of strategic development of the livestock industry. In the course of the research, special scientific methods were used: monographic, abstract-logical, analytical, scenario forecasting method, as well as general methods of scientific knowledge: observation, analysis, comparison, generalization.

\section{Results and discussion}

The Bryansk Region is a region with an intensively developing agro-industrial complex. During the last period, intensive modern technologies are widely used in the production of livestock products in the agriculture of the region, energy-saturated equipment is used to reduce manual labor, and scientific developments are increasingly used in real production. Meat cattle breeding, poultry farming and pig farming were widely developed. At present, modern facilities for growing and processing of meat products have been put into operation and are being built. Thus, the Bryansk Meat Company opened a factory of ready-made culinary dishes in 2019. In addition, it is close to the completion of a specialized feedlot for the simultaneous maintenance of 80 thousand cattle heads $[7,8]$.

Miratorg Agro-Industrial Holding is currently implementing a project to increase the facility for growing and processing broiler chicken meat. The area of pig products production is expanding rapidly. Thus, two pig-breeding complexes are under construction. The construction of the rabbit breeding complex by the Krolkovo Agricultural Holding is being completed. Agroholding "OKHOTNO" in the Brasovsky district is building a dairy farm with a capacity of 3.6 thousand heads of dairy herd [9].

Agriculture has a certain state support for the development of dairy and meat cattle breeding, poultry and pig breeding, and animal breeding. 
Table 1. Cattle, poultry, rabbit livestock, the number of bee colonies in farms of all categories of the Bryansk region in 2005-2019, thousands of heads.

\begin{tabular}{|l|c|c|c|c|c|c|c|}
\hline \multicolumn{1}{|c|}{ Indicators } & $\mathbf{2 0 0 5}$ & $\mathbf{2 0 1 0}$ & $\mathbf{2 0 1 7}$ & $\mathbf{2 0 1 8}$ & $\mathbf{2 0 1 9}$ & \multicolumn{2}{c|}{$\mathbf{2 0 1 9}$ in \% to } \\
\cline { 3 - 8 } & & & & & & $\mathbf{2 0 0 5}$ & $\mathbf{2 0 1 8}$ \\
\hline Cattle & 236.3 & 182.2 & 462.6 & 491.2 & 482.5 & 204.2 & 98.2 \\
\hline including cows & 125.1 & 94.9 & 195.4 & 199.6 & 196.3 & 156.9 & 98.3 \\
\hline Pigs & 120.0 & 157.4 & 295.5 & 306.1 & 313.8 & 261.5 & 102.5 \\
\hline Sheeps and goats & 30.1 & 34.3 & 29.8 & 25.8 & 24.7 & 82.1 & 95.7 \\
\hline Birds & 3794.8 & 6857.4 & 14750.2 & 14828.6 & 13234.3 & $3.5 \mathrm{p}$. & 89.3 \\
\hline Rabbits bee & 8.7 & 20.9 & 41.6 & 66.5 & 89.1 & $10.2 \mathrm{p}$. & 133.9 \\
\hline $\begin{array}{l}\text { Number of } \\
\text { colonies, thousands }\end{array}$ & 16.9 & 18.7 & 18.9 & 17.4 & 17.2 & 101.8 & 98.9 \\
\hline
\end{tabular}

The analysis of the number of cattle showed that in general it increased by 2 times (Table 1). Since 2011, a new producer of cattle for meat AIH "Miratorg" has appeared on the territory of the region. With its appearance, the industry has made a significant step forward and in 2017 the total number of cattle increased by 2.6 times compared to 2010 . In 2019 , it amounted to 482.5 thousand heads, which is $1.8 \%$ lower than the level of the previous 2018. Cattle is raised and fattened in almost all districts, but the largest share falls on Trubchevsky, Pochepsky, Vygonichsky, Starodubsky, Klimovsky and Mglinsky districts.

Pig farming is also developing on the territory of the region. Mainly pig breeding complexes are located in Zhiryatinsky, Vygonichsky, Karachevsky and Bryansk districts. Thus, in 2019 , the number of pigs increases by 2.6 times compared to 2005 . If we analyze the history of changes dynamics in the number of pigs in the Bryansk region, we can note that the largest number falls on 1977 and amounted to 754.0 thousand heads. Then there is a decrease in its number, the smallest number is in $2005-120.0$ thousand heads. Then there is its constant growth and in 2019 the number of pigs amounted to 313.8 thousand heads.

Pig breeding has now received a broad impulse for development in the Bryansk region. The Zhukovsky district is an example, where a large investment project is being implemented to build a pig complex for 3,000 heads. 2.1 billion rubles have been invested in this project, which is being implemented by the Agroholding "OKHOTNO" $[10,11]$.

Sheep and goats are raised mainly in the households. Thus, in $2019-82.1 \%$, the livestock is grown in personal subsidiary plots, $14.1 \%$ in peasant (farm) farms and $3.2 \%$ in agricultural enterprises. The largest number of sheep and goats in the Bryansk region falls on the pre-revolutionary year of 1915 and amounted to 778.0 thousand heads, then their number declines. Thus, in 2019, compared to 2005, there is a decrease in the number of sheep and goats by $17.9 \%$ and it also decreases by $4.3 \%$ compared to 2018 . In general, sheep and goat farming is an inefficient industry and is almost disappearing.

Poultry farming is also a priority industry in the region, which is developing at a significant pace. Thus, the growth of the poultry population was 3.5 times, relative to 2005 . Moreover, the development of meat broiler poultry farming mainly prevails on the territory of the region. In recent years, the meat and poultry industry has been developing rapidly, which is due to the built-up effective management vertical, which allows to preserve the scientific and production system, through which the economic policy of the poultry industry is implemented.

The effective activity of the poultry industry is due to the use of scientific developments of the branch institutes of the Federal Research Center "All-Russian Research Institute of Poultry" of the Russian Academy of Sciences and its branches of the Federal Research Center VNITIP RAS, "VNIIPP", "VNIVIP", "FTSOZH". These scientific institutions, working on the program "Creating a domestic competitive cross of meat chickens for the purpose of broilers obtaining" (for the period 2020-2025), provide enterprises with 
domestic cross, characterized by high productivity and viability [12].

Rabbit breeding has been developing rapidly in the region in recent years. Thus, in 2019, the growth was 10.2 times, compared to 2005. This increase is due to the appearance of FH (YL) "SVK Agro" on the territory of the region in the Karachevsky district, it built a modern rabbit breeding complex, which in the future can become the leader of industrial rabbit breeding in the Russian Federation. A particularly significant increase occurred in 2019 , even compared to the previous 2018, the growth was $33.9 \%$, which positively characterizes the development of this livestock industry.

In the future, the existing complex will be able to increase the population up to 10 thousand heads of doe rabbits and 100 thousand heads of highly productive rabbits. The breed of rabbits of the Hy-Cole line brought from France is used. In the future, the production output will be at least 400 tons of meat annually. The new workshops of the rabbit-breeding enterprise have a full production cycle - their own highly productive livestock, a veterinary point for animal treatment, a workshop for the maintenance of males, a selection department, a modern slaughterhouse, a primary processing workshop, an automated packaging line, chambers for product cooling and freezing, a storage and disposal workshop. It is planned to use the most advanced world technologies.

The production of livestock and poultry for slaughter (in carcass weight) increased 6.2 times over the analyzed period and amounted to 329.4 thousand tons in 2019 (Table 2). This increase was mainly due to a significant increase in poultry meat production - 22.4 times, and the production of cattle for meat, pigs, sheep and goats is also significantly increasing.

The structure of livestock and poultry production for slaughter in carcass weight varies significantly by year. Thus, if in 2005 the largest share fell on the products of pig breeding $-40.9 \%$, then, in 2019 , the main position is occupied by poultry products $-65.9 \%$. The structure of livestock and poultry production for slaughter has changed dramatically. There are a number of poultry farms - JSC "Kurinoye Tsarstvo - Bryansk", CJSC "Pobeda-Agro", LLC "Bryansky broiler" (AIH Miratorg) on the territory of the region. The largest poultry farms are JSC "Kurinoye Tsarstvo - Bryansk" and LLC "Bryansky broiler" (AIH Miratorg).

AIH Miratorg is the largest producer of chicken in the Russian Federation, which has opened a high-tech production of full-cycle poultry meat "from the field to the counter". The poultry farms of this company are located in Vygonichsky and Trubchevsky districts, consisting of 20 poultry breeding plots of the parent herd and repair young animals, 7 broiler poultry farms, 1 meat processing plant. The capacity of this enterprise is constantly increasing.

Table 2. Production of the main products of animal husbandry in farms of all categories of the Bryansk region in 2005-2019

\begin{tabular}{|c|c|c|c|c|c|c|c|}
\hline \multirow[t]{2}{*}{ Indicators } & \multirow[t]{2}{*}{2005} & \multirow[t]{2}{*}{2010} & \multirow[t]{2}{*}{2017} & \multirow[t]{2}{*}{2018} & \multirow[t]{2}{*}{2019} & \multicolumn{2}{|c|}{2019 in \% to } \\
\hline & & & & & & 2005 & 2018 \\
\hline $\begin{array}{l}\text { Cattle and poultry for } \\
\text { slaughter } \\
\text { (in carcass weight), } \\
\text { thousand tons }\end{array}$ & 53.1 & 89.0 & 316.0 & 325.2 & 329.4 & $6.2 \mathrm{p}$ & 101.2 \\
\hline \multicolumn{8}{|l|}{ including: } \\
\hline cattle & 19.5 & 16.2 & 47.2 & 51.8 & 53.1 & 272.3 & 102.5 \\
\hline pigs & 21.7 & 24.5 & 51.3 & 53.6 & 56.3 & 259.4 & 105.0 \\
\hline sheeps and goats & 0.5 & 1.0 & 0.9 & 0.8 & 0.9 & 180.0 & 112.5 \\
\hline poultry & 9.7 & 45.4 & 214.8 & 217.0 & 217.1 & $22.4 \mathrm{p}$. & 100.0 \\
\hline Milk, thousand tons & 437.7 & 337.3 & 293.6 & 291.4 & 293.2 & 67.0 & 100.6 \\
\hline Eggs, million pieces & 414.3 & 319.1 & 386.4 & 367.8 & 276.7 & 66.7 & 75.2 \\
\hline Honey, tons & 291 & 183 & 242 & 391 & 470 & 161.5 & 120.2 \\
\hline
\end{tabular}

A decrease in milk production is a negative factor in the use of the resource potential, 
which is exclusively due to a decrease in the number of animals of the main herd, with an increase in the average annual milk yield per 1 cow to $5222 \mathrm{~kg}$. At the same time, the productivity of cows in agricultural enterprises in 2019 was $5105 \mathrm{~kg}$.

Breeding work is constantly carried out on the territory of the region to increase the genetic potential of the main herd of animals (cow productivity). So there are 6 breeding plants and 10 breeding producers of dairy products. They contain 29.6 thousand heads of breeding cattle, including 12 thousand cows. Replenishment of the region's dairy herd is also carried out at the expense of cattle raised in the region's breeding farms.

The strategy for the development of dairy cattle breeding in the Bryansk region can be justified taking into account three scenarios: inertial, innovative local and innovative system. Each of these scenarios has its own characteristics related to the production and consumption of dairy products $[13,14]$.

The inertial scenario assumes the preservation of the cattle population while maintaining the rate of increase in cow productivity. The innovation process involves the gradual introduction of innovative solutions that cover individual technological operations, that is, partial improvement of the production process. The innovative system scenario is the renewal of the resource base of dairy cattle breeding through the construction of dairy farms and complexes, mechanization and automation of work processes, and use of cows with high genetic potential for productivity in the production process.

The scenarios of the strategic development of dairy and beef cattle breeding (Figs. 1 and 2 ) of the Bryansk region are selected based on the analysis of restraining and stimulating factors that are possible in agricultural production.

When forecasting the gross milk production, marketability level of milk and current trends in the development of dairy cattle breeding in farms of different categories were taken into account. In the future, the productivity of dairy cattle should become a determining factor in milk production increase. This is possible due to the activation of breeding work in the industry.

The scenario for meat production development in the region assumes an increase in the production of livestock and poultry meat starting in 2020 due to the expansion of the production activities of existing agricultural enterprises and agricultural holdings.

The volume and efficiency of beef cattle breeding is influenced by the following factors: system and volume of state support, meat market conditions and production resources, etc.

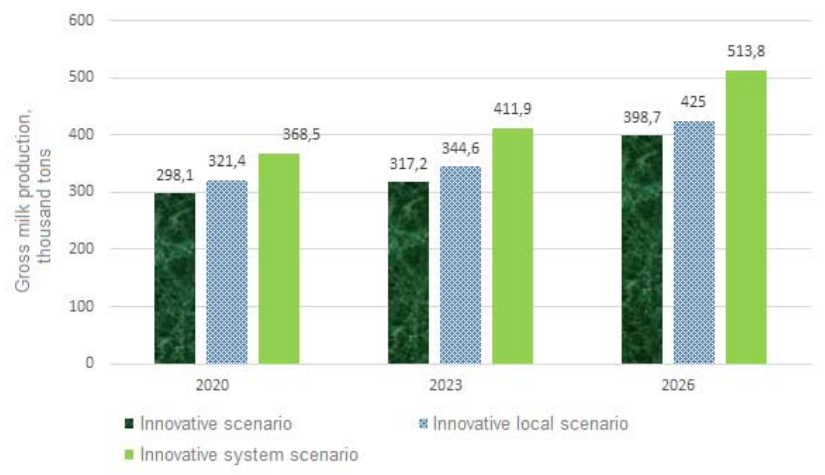

Fig. 1. Forecast of gross milk production in farms of all categories of the Bryansk region for the period up to 2026, thousand tons.

The development of dairy cattle breeding in the Bryansk region can significantly increase the use of the resource potential of animal husbandry. For these purposes, three major investment projects are being implemented for the construction of dairy complexes in 
LLC "Krasny Oktyabr", JSC "Zheleznodorozhnik" and LLC "Druzhba-2" [15].

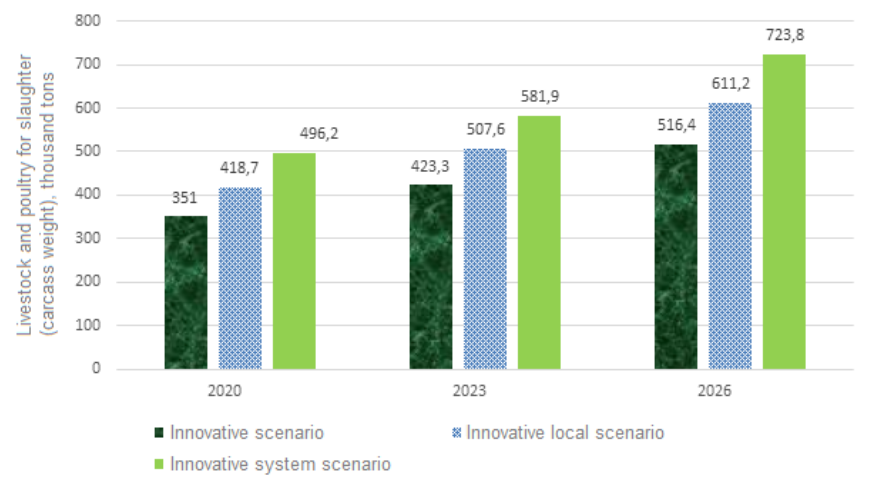

Fig. 2. Forecast of gross production of livestock and poultry meat in farms of all categories of the Bryansk region for the period up to 2026, thousand tons.

The efficiency of the industry development is greatly influenced by the animal productivity. Thus, the milk yield per cow increases by 2.1 times and amounted to $5222 \mathrm{~kg}$ in 2019. (Table 3). At the same time, the gross milk production is reduced as a result of a reduction in the number of animals. The main milk producers are Starodubsky, Bryansky, Komarichsky, Pogarsky and Sevsky districts. The leading companies in terms of average annual milk yield and milk production are such enterprises as LLC "Niva", LLC "Krasny Oktyabr", LLC "Russkoye Moloko", LLC "Yjvy Put", SEC "Zimnitsky", collective farm "Progress".

Table 3. Productivity of cattle and poultry in farms of all categories of the Bryansk region in 20052019.

\begin{tabular}{|c|c|c|c|c|c|c|c|}
\hline \multirow[t]{2}{*}{ Indicators } & \multirow[t]{2}{*}{2005} & \multirow[t]{2}{*}{2010} & \multirow[t]{2}{*}{2017} & \multirow[t]{2}{*}{2018} & \multirow[t]{2}{*}{2019} & \multicolumn{2}{|c|}{2019 in $\%$ to } \\
\hline & & & & & & 2005 & 2018 \\
\hline Milk yield per cow, $\mathrm{kg}$ & 2501 & 2875 & 4470 & 4684 & 5222 & 208.8 & 111.5 \\
\hline $\begin{array}{l}\text { Average annual egg } \\
\text { production of laying hens, } \\
\text { pcs. }\end{array}$ & 291 & 260 & 247 & 242 & 185 & 63.6 & 76.4 \\
\hline $\begin{array}{l}\text { Average daily weight gain of } \\
\text { cattle, g }\end{array}$ & 230 & 222 & 463 & 515 & 463 & 201.3 & 89.9 \\
\hline $\begin{array}{l}\text { Average daily weight gain of } \\
\text { pigs, g }\end{array}$ & 241 & 479 & 641 & 600 & 600 & 248.9 & 100.0 \\
\hline
\end{tabular}

The average annual egg production of laying hens is significantly reduced $-36.4 \%$ and amounted to only 185 pieces in 2019 . This is a very low indicator and the enterprises of the region need to find ways to increase this indicator.

The average daily weight gain of cattle, in grams, increases significantly - by 2.0 times, but decreases relative to the previous 2018 by $10.1 \%$. The increase in this indicator is due to the intensification of the beef cattle industry. The average daily weight gain of pigs, in grams, increases by 2.5 times, which is positive and caused by the development of the industry.

Egg production of laying hens is also a significant potential of the region, which is not used to its full potential. Thus, the production of this most valuable type of product during the analyzed period is significantly reduced - by $33.3 \%$. On average, 230 eggs are produced per 1 inhabitant of the region, which is significantly lower than the standard value (263 eggs). In addition, one resident of the region actually consumes -240 eggs in 2019 . That is, there is an under-production of this product in the region and some of it is imported from 
other regions.

The natural conditions of the Bryansk region are favorable for beekeeping development. Thus, there are forests, hayfields, pastures, floodplain meadows and acreage in sufficient quantities. In the forests there are a large number of trees and shrubs with nectariferous flowering, including linden, viburnum, acacia, bird cherry, mountain ash, blueberry, lingonberry and other nectariferous plants. A large number of cultivated honey plants, such as rapeseed, buckwheat, sunflower, sweet clover and other crops, are grown on arable land.

Honey production in the region increases by $61.5 \%$, which positively characterizes the development of the industry. At the same time, the number of bee colonies increases slightly, which indicates an increase in bee colony productivity.

Beekeeping is carried out unevenly on the territory of the Bryansk region. A larger number of bee colonies are located on the territory of the Bryansk, Dyatkovsky, Vygonichsky and Zhukovsky districts. In addition, large-scale beekeeping is practically absent, thus, $92 \%$ of bee colonies are concentrated in small amateur beekeepers, where there are from 5 to 25 bee colonies. The largest beekeeping apiary has 120 bee colonies. According to calculations, one bee family produces about $25.19 \mathrm{~kg}$ of gross and $14.7 \mathrm{~kg}$ of commercial honey. The highest productivity of bee colonies is observed in the southern parts of the region. In general, the development of beekeeping in the region has great prospects, which are still little used.

The level of beekeeping development remains almost unchanged and in 2019 there are 17.2 thousand of bee colonies in the region. Moreover, in 2018-2019, there is a slight decrease. The decline in bee colonies in the region is due to the fact that in recent years there has been a reduction in abandoned uncultivated land and the use of intensive technologies in crop production leads to the death of bees.

\section{Conclusions}

The number of livestock, poultry, rabbits, the number of bee colonies in farms of all categories of the Bryansk region in 2005-2019, in thousands of heads, significantly increases, which has a positive impact on the development of animal husbandry and agriculture in general. The production of the main products of animal husbandry in farms of all categories is increasing, with the exception of the production of milk and eggs. The productivity of livestock and poultry in farms of all categories also increases significantly, with the exception of the average egg-laying capacity of laying hens. In general, animal husbandry in the Bryansk region is actively developing $[16,17]$.

State support plays a significant role in the innovative development of animal husbandry in the Bryansk Region. The region has developed and operates the State Program "Development of agriculture and regulation of markets for agricultural products, raw materials and food in the Bryansk region". The main goals of innovative and progressive development of the livestock industry in the region are the following: stimulating growth of livestock production, aimed at import substitution; increasing competitiveness of livestock products and financial stability of enterprises; reproduction and increasing efficiency of using the resource potential of livestock industry; ensuring sales and increasing the marketability of livestock products by creating conditions for their storage and processing; modernization of material and technological base of livestock; support for small businesses.

The regional strategy for the development of animal husbandry includes promising investment projects, implementation of which will increase the capacity for domestic product production. The strategic goal is to form a stable trend of progressive development of the livestock industry on an innovative basis. 


\section{References}

1. S.A. Belchenko, V.E. Torikov, V.F. Shapovalov, O.V. Dyachenko, I.N. Belous, Bulletin of the Bryansk State Agricultural Academy, 1(65), 35 (2018)

2. S.A. Belchenko, A.V. Dronov, V.E. Torikov, I.N. Belous, Actual tasks for the development of the food sector of the agro-industrial complex of the Bryansk region, 9 , 3 (2016)

3. M.A. Borisenko, A.A. Kuzmitskaya, In the collection: Scientific discussion of modern youth: current issues of the state and prospects of innovative development of the economy, 21 (2019)

4. V.F. Vaskin, T.I. Vaskina, X International Scientific and Practical Conference, 63 (2019)

5. V.F. Vaskin, Materials of the scientific and practical conference, 18 (2014)

6. V.F. Vaskin, V.I. Repnikova, XI International Scientific and Practical Conference, 83 (2020)

7. O.V. Dyachenko, XII International Scientific and Practical Conference, 174 (2017)

8. A.A. Kuzmitskaya, E.N. Kislova, M.A. Babyak, E.E. Babyak, Bulletin of the Bryansk State Agricultural Academy, 3, 208 (2013)

9. O.N. Korosteleva, S.V. Sevryukova, A.A. Rybikova, Nikonov Readings, 22, 186 (2017)

10. A.I. Korostelev, O.N. Korosteleva, A.A. Rybikova, International Journal of Experimental Education, 4(2), 442 (2015)

11. V.A. Malyavko, I.V. Malyavko, Actual problems of veterinary medicine and intensive animal husbandry, 185 (2013)

12. E.P. Chirkov, Development of the organizational and economic mechanism in the system of agro-industrial production management in the region, 350 (2014)

13. A.A. Kuzmitskaya, Faculty of Economics, 12 (2011)

14. K.V. Tolstoshein, International Agricultural Journal, 3, 42 (2016)

15. V.E. Torikov, N.V. Podobay, Agroconsultant, 4, 45 (2017)

16. I.N. Belous, Amazonia Investiga, 8(23), 759 (2019)

17. I.N. Belous, Ecology, Environment and Conservation, 23(4), 1991 (2017) 